\title{
Does workplace bullying experiences impact, on long-term, employees levels of strain?
}

\author{
Teodora Maidaniuc-Chirilă, \\ Motivation, Self and Well-Being research center, Psychology Department, Alexandru Ioan Cuza University, \\ Iasi, Romania
}

\begin{abstract}
The present study reports the long-term effects of workplace bullying exposure on Romanian employees' physical strain. 73 (Mage=31.5; SDage=8.91) Romanian employees participated at baseline ( $\mathrm{t} 1$ June-September 2012) and at follow-up six months later (t2. March 2013- June 2013).

The results of the present article showed that workplace bullying consequences are more important for the longterm than for the short one. The results showed that workplace bullying predicted at time 1 only $6.2 \%$ of physical strain's variance while at time 2 it predicted $13.1 \%$ of physical strain's variance.

These results emphasize that the more prolonged are workplace bullying acts the more physically strain Romanian employees will feel. It seems that the negative effects of workplace bullying exposure are more salient on long-term than on short-term.

The results of the present article can have practical implications because they can bring new information useful for human resources practitioners, helping them designing and conducting more efficient training programs.
\end{abstract}

Key words: workplace bullying, physical strain, long-term effects, cross-lagged panel design, regression analyses

\section{INTRODUCTION}

Workplace bullying has been classified as an extreme social stressor in work contexts, and as one of the more devastating problems as compared to other work-related stressors (Einarsen \& Mikkelsen, 2003; Zapf, Knorz \& Kulla, 1996).

Even though no general definition of workplace bullying has been accepted, most definitions refer to aspects such as the persistence of bullying and the negative or detrimental effects perceived by the victim (Cusack, 2000).

Bullying at work, according to most definitions, takes place when someone, repeatedly over a longer period of time (usually six months), is exposed to negative acts from one or several others, in a situation where he or she for different reasons may have difficulties defending him- or herself against these actions (Einarsen, 2000; Salin, 2003; Zapf, Einarsen, Hoel \& Vartia, 2003).

The current study aligns with the European perspective which defines bullying as: "[...] harassing, offending, socially excluding someone or negatively affecting someone's work tasks. In order for the label bullying to be applied to a particular activity, interaction or process it has to occur repeatedly and regularly (e.g. weekly) and over a period of time (e.g. six months). Bullying is an escalated process in the course of which the person confronted ends up in an inferior position and becomes the target of systematic negative social acts" (Einarsen, Hoel, Zapf \& Cooper, 2003, p.15).

Workplace bullying may take different forms. Direct bullying is aggressive acts that are aimed directly at the target (i.e. teasing, scolding, spreading rumours, and threats). Indirect bullying may take the form of social isolation or withdrawal of necessary information (Hansen, Hogh, Persson, Karlson, Garde \& Orbaek, 2006). Bullying may be work-related (i.e. acts that make it difficult for the targets to do their work) or personal (i.e. offending, teasing, rumours, slander, or sexual harassment) and one of the its characteristics is the inequality in power between the perpetrator and the target (Einarsen, 2000; Einarsen \& Mikkelsen, 2000; Neuman \& Baron, 1997). Either supervisors are directly involved or the bullying takes place between co-workers, where the perpetrator, for some reason or another, is stronger than the target is. Even supervisors may be bullied by subordinates, especially if the subordinates act in groups (Salin, 2003; Zapf \& Einarsen, 2001).

Workplace bullying is assumed to have a strong impact on the mental health of those affected (Einarsen, 2000), thus being subjected to bullying may have severe psychological and physiological health consequences for the target. A number of cross-sectional studies have found correlations between bullying, on one hand, and on the other, chronic fatigue, psychosomatic, psychological and physical symptoms, general stress, and mental stress reactions (Einarsen \& Mikkelsen, 2000; Dofradottir \& Hogh, 2002).Several studies have shown that bullying is associated with severe health problems, such as sleep disturbances, anxiety,

DOI: 10.9790/0837-2107064853 $\quad$ www.iosrjournals.org $\quad 48 \mid$ Page


depression, posttraumatic stress disorder, and psychosomatic symptoms (Zapf, Knorz \& Kulla, 1996; Hansen et al., 2006; Vartia, 2001; Rayner, Hoel \& Cooper, 2002; Einarsen \& Mikkelsen, 2003; Niedhammer, David \& Degioanni, 2006; Notelaers, Einarsen, De Witte, \& Vermunt, 2006).

Results based on cross-sectional design does not permit conclusions in terms of causality and few studies (Kivimaki, Virtanent, Vartia, Elovainio, Vahtera, \& Keltikangas-Jarvinen, 2002; Hogh, Henrikssen \& Burr, 2005) have investigated the long-term effects of bullying with longitudinal design (Rodriguez-Munoz, Baillien, De Witte, Moreno-Jimenez \& Pastor, 2009) so that present article tries to fulfill this gap by presenting longitudinal results of workplace bullying on employees' physical strain.

Several authors have underlined the importance of temporal lag in longitudinal designs when exploring cross-lagged effects (Steinmetz, Frese \& Schmidt, 2008; Taris \& Kompier, 2003). In occupational health research, there is little uniformity in the recommendations concerning the length of the time lags (RodriguezMunoz et al., 2009). Most studies in the work stress literature have applied time lags of up to one year for exploring stressors-strain relationships, and have concluded that one-year time lag is appropiate for demonstrating the causal relationships among these variables (De Lange, 2005). Moreover, Dormann and Zapf $(1999 / 2002)$ found the strongest effects for time lags of eight months and two years when examining the effects of social stressors at work on depressive symptoms. Rospenda, Richman and Shannon (2006), using a time lag of three years, found a cross-lagged effect of harassment on hostility and drinking problems. As a majority of longitudinal studies have employed time lags of one year, De Lange, Taris, Kompier, Houtman, and Bongers (2004) called for more longitudinal research with shorter time lags. In this way, more insight could be obtained into the shorter term consequences of work characteristics on well-being (Rodriguez-Munoz et al., 2009). In addition, regarding the selection of temporal lag between measurements, several authors have pointed out that it should correspond with the "causal interval" of the process under study (De Lange, 2005; Taris \& Kompier, 2003). In this sense, as the minimum period for workplace bullying to develop is six months (Einarsen et al., 2003), a time lag shorter than six months it is not appropiate.

This study aims to increase knowledge about workplace bullying-strain associations over time, thus addresing an important limitation of previous research in this field. This study will analyse the relationships existing between workplace bullying and Romanian employees' physical strain with a time-lag of six months.

\section{PROSPECTIVE STUDIES SHOWING WORKPLACE BULLYING'S LONG-TERM EFFECTS}

Using a prospective design, the present study wants to determine the relationship between workplace bullying exposure and Romanian employees' physical strain and to test whether the long-term effect is bigger than the short one.

Previous research using longitudinal studies have explained that some people may have difficulties performing their jobs and therefore be perceived as "weak", or exhibit certain behaviors that trigger bullying behavior from other people (Finne, Knardahl \& Lau, 2011).

So far, these relationships between workplace bullying exposure and health outcomes were studied using only cross-sectional data and few studies (Hansen et al., 2006; Finne et al., 2011; Nielsen, Hetland, Matthiesen \& Einarsen, 2012; Rugulies, Madsen, Hjarbech, Hogh, Borg, Carneiro \& Aust, 2012) studied these relationships using longitudinal designs. The present study tries to fulfill this gap by investigating the long-term relationships between workplace and employees' physical strain.

Kivimaki and colleagues (2002) in their longitudinal study employing a cross-lagged panel design have shown that there is a cumulative relation between workplace bullying and the incidence of depression: the longer the exposure to bullying, the greatest the risk of depression. Furthermore, through their longitudinal design, Kivimaki and colleagues (2002) managed to demonstrate that high levels of depression predicted new cases of workplace bullying. According to the authors, the process of bullying may actually include characteristics of a vicious circle in which mental health problems are a result of bullying and increase susceptibility of bullying.

Furthermore, using the same design as Kivimaki and colleagues (2002) to investigate the relationship between workplace bullying and mental distress, Finne, and colleagues (2011) found that those who reported bullying at baseline and follow-up or at either of the time points reported more mental distress than did employees who didn't report bullying. Even though the results showed these differences among employees at to different times, mental distress wasn't a significant predictor of workplace bullying, and authors explained the lack of predictive power by the small number of participants. Moreover, Brousse and colleagues (2008) found that $51 \%$ of respondents of the two studies had reported a prolonged bullying that lasted for more than two years. Four years later, Nielsen and colleagues (2012) found that the exposure to bullying acts at baseline increased the symptomatic distress two years later, and psychological distress predicted both exposure to bullying behaviors and victimization from bullying, thus suggesting that psychological distress is an etiological factor for exposure to workplace bullying. More over, a Danish 5-year perspective longitudinal cohort study 
investigating long-term effects of exposure to workplace bullying showed that harassment and mental health mutually influenced each other (Hogh et al., 2005).

Rodriguez-Munoz, Moreno-Jimenez and Sanz-Vergel (2015) found on a cross-lagged panel of 348 employees that workplace bullying at baseline (i.e. t.1.) was positively and significantly associated with employees anxiety at follow-up (i.e. t2) meaning that worklace bullying has a negative impact on long-term on employees' levels of anxiety.

\section{AIM OF THE PRESENT STUDY}

Most empirical evidence about the effects of workplace bullying has been based on cross-sectional designs, which does not permit conclusions in terms of causality (Rodriguez-Munoz et al., 2009). Accordingly, despite the recent proliferation of research on bullying, very little is known about how bullying impacts on longterm employees' health.

Using a longitudinal design, the aim of the first study is to determine the long-term effects of workplace bullying on Romanian employees' physical strain.

\section{HYPOTHESIS} short ones.

The long-term effects of workplace bullying exposure on physical strain will be more salient the the

\section{INSTRUMENTS}

The instruments measuring workplace bullying and physical strain were translated into Romanian using the back-method translation procedure. The authors of the original instruments were contacted through email in order to get the permission to use the instruments.

\section{a. Workplace bullying}

Workplace bullying was measured with the Romanian version of Einarsen, Hoel and Notelaers' (2009) Negative Acts Questionnaire-Revised (translated and adapted by Chirila \& Constantin, 2014). The Negative Acts Questionnaire-Revised (NAQ-R) has 22 items referring to 22 behavioral negative acts grouped in three dimensions (i.e. intimidation, person-related bullying and work-related bullying). The response to this questionnaire was given on a five-point Likert scale were 1 meant never and 5 meant daily. The Cronbach's alpha for the entire questionnaire is $\alpha=.92$, with $\alpha=.84$ for intimidation, $\alpha=.78$ for context-related bullying and $\alpha=.92$ for intimidation.

\section{b. Physical strain}

One scale measuring physical strain from Occupational Stress Inventory (Evers, Freese \& Cooper, 2000) was used. Participants were told to answer to these items by referring to their past six months. The responses were given on six-point Likert frequency scale were 1 meant never and 5 meant always. Physical strain scale consisted of 12 items with $\alpha=.82$.

\section{Participants}

A number of 73 (Mage= 31.5; SDage=8.91) Romanian employees participated at the present study by completing on-line questionnaires measuring workplace bullying and mental and physical strain in two different moments (t1-between June-September 2012 and t2-between March-June 2013) with a time-lagg of six months. The questionnaires were completed during employees' free time.

$59(80.8 \%)$ employees were female participants and $14(19.2 \%)$ were male participants with ages between 19 and 60 years. Six (8.2\%) participants had a high-school diploma, 24 (32.9\%) participants had a bachelor degree and $43(58.9 \%)$ had a master degree. 31 (42.5\%) employees are working in public institutions and $42(57.5 \%)$ employees are working in private firms. They are working in different sectors of activities such as retail (5/6.8\%), sales (25/34.2\%), services $(5 / 6.8 \%)$ and education $(38 / 52.1 \%)$.

The study was presented as being one interesting in the investigation of interpersonal workplace dynamics and expression such as harassment, workplace violence, workplace abuse were not presented in the instructions paragraph. 


\section{RESULTS}

Table 1. Means, standard deviations and correlations among variables measured at basis (i.e. June-September 2012) and at the follow up (i.e. March-June 2013)

\begin{tabular}{l|llllll}
\hline & $M$ & $S D$ & 1 & 2 & 3 & 4 \\
\hline 1. Workplace bullying (t1) & 1.60 & .48 & 1 & & & \\
2. Workplace bullying (t2) & 1.61 & .48 & $.716^{* *}$ & 1 & & \\
3. Physical strain (t1) & 5.08 & .47 & $.275^{*}$ & .216 & 1 & \\
4. Physical strain (t2) & 2.37 & .83 & $.378^{* *}$ & $.537^{* *}$ & $.441^{* *}$ & 1 \\
& & & & & & \\
& $*, \mathrm{p}<.05 ; * *, \mathrm{p}<.01$
\end{tabular}

The results from table 1 shows that workplace bullying measured at baseline is positively and significantly correlated with workplace bullying measured at follow up. Furthermore, workplace bullying measured at baseline (i.e. t1) is positively correlated with physical strain at baseline (i.e. $\left.r=.275^{*}, p<.05\right)$ and also positively correlated with physical strain at follow-up (i.e. $r=.378^{* *}, \mathrm{p}<.01$ ).

Workplace bullying at follow-up (i.e. t2) is positively and significantly correlated with physical strain at follow-up (i.e. $\mathrm{r}=.537, \mathrm{p}<.001$ ).

Physical strain at baseline (i.e. t1) is significantly and positively correlated with physical strain at follow-up (i.e. $\mathrm{r}=.441 * *, \mathrm{p}<.001)$.

Table 2. Regression model predicting physical strain at the basis and at follow-up

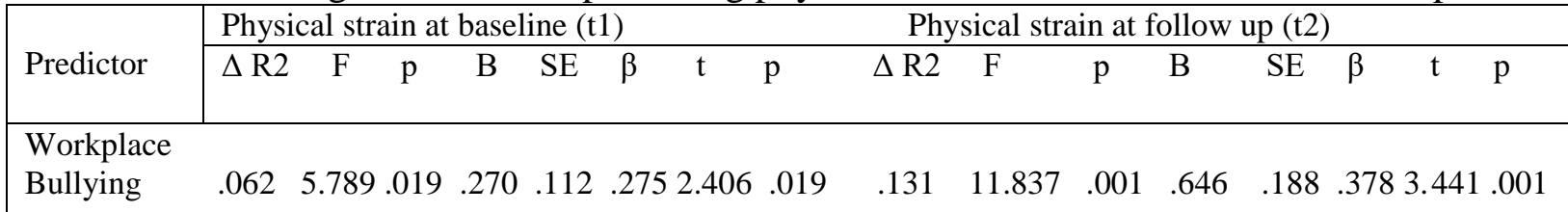

\section{$N=73$.}

Measured at the baseline (i.e. t1), workplace bullying predicts $6.2 \%$ from physical strain variances, measured also at baseline (i.e. T1). workplace bullying at baseline (i.e. t1) predicts $13.1 \%$ from physical strain's variance measured at follow-up (i.e. t2) meaning that, on long-term, workplace bullying leads to an increased of physical strain.

\section{DISCUSSIONS}

The present study shows the longitudinal relationships between workplace bullying and Romanian employees' physical strain. The time lag between the two measurements was six months.

The correlations showed that workplace bullying at baseline (i.e. t1) is correlated with physical strain at baseline (i.e. t1) and with physical strain at follow-up (i.e. t2). Workplace bullying exposure at follow-up (i.e. t2) is correlated with physical strain at follow-up (i.e. t2).

The regression analyses showed that workplace bullying exposure at the baseline (i.e. t1) predicted not only Romanian employees' physical strain at the baseline (i.e. t1), but also Romanian employees' physical strain at follow-up (i.e. t2).

These results showed that prolonged exposure to workplace bullying acts has not only a short-term negative effect on employees' strain but also a long-term negative effect and that the long-term negative effect is bigger the short one.

This study managed to reveal that workplace bullying exposure effects are more detrimental on the long term and if they aren't properly managed by the organization or by the human resources department the affected employees will experience higher levels of mental distress and illnesses and in the end will leave the organization.

These results are convergent to those already presented in the workplace bullying literature in which it was shown that prolonged exposure to workplace bullying predicted long-term negative effects on employees' levels of health. So that, if previously Kivimaki and colleagues (2002) showed that the longer the employees are exposed to workplace bullying acts the more depressed they'll feel, the present study showed that the longer the Romanian employees' are exposed to workplace bullying acts the more physically strained they'll feel six months later. Three years later, Hogh and colleagues (2005) using a prospective design found that exposure to workplace bullying and employees' health mutually influenced each other. The more the employee is exposed to workplace bullying acts the less healthy he will feel and the more exposed to future workplace bullying acts will 
be. Furthermore, Finne and colleagues (2011) showed that on long-term, exposure to workplace bullying affects employees' levels of mental distress so that the longer the employees is exposed to workplace bullying acts the more mentally distressed he will feel two years later. More over, Nielsen and colleagues (2012) found that bullying at baseline predicted an increased level of symptomatic distress two years later.

Using a prospective design, the present study confirmed the results existing in the literature in which it was shown that prolonged exposure to workplace bullying will predict later negative outcomes in employees' physical strain.

\section{Limitations for the present study}

One of the limits of the present study consists of the small number of employees participating at the follow up so that extrapolating this results to the entire population of Romanian employees should be made with caution.

\section{Practical implications}

The results reported in this study have practical implications for human resources practitioners in that they can develop more efficient training programs in which they can inform employees on the long-term effects of prolonged exposure to workplace bullying acts. Furthermore, they can develop more efficient anti-bullying organizational policies in order to stop and to punish these type of acts within the entire organization.

\section{ACKNOWLEDGEMENTS}

This paper has benefited from financial support from the strategic grant POSDRU/88/1.5/S/47646, co-financed by the European Social Fund, within the Sectorial Operational Program - Human Resources Development 20072013.

[1] Brousse, G., Fontana, L., Ouchchane, L., Boisson, C., Gerbaud, L., Bourguet, D. et al. (2008). Psychopathological features of a patient population of targets of workplace bullying. Occupational Medicine, 58(2), 122-128.

[2] Chirilă T. \& Constantin T. (2014). Verifying the psychometric properties of two instruments measuring workplace bullying among Romanian employees. Annals of Alexandru Ioan Cuza University, Psychology Series, 3(1), 91-109, ISSN: 2069-1386.

[3] Cusack, S. (2000). Workplace bullying: icebergs in sight, sounding needed. Lancet, 356, 2118.

[4] De Lange, A.H.,Taris, T.W., Kompier, M.A.J., Houtman, I.L.D. \& Bongers, P.M. (2004). The relationships between work characteristics and mental health:Examining normal, reversed and reciprocical relationships in a 4-wave-study. Work \& Stress, 18, 149-166.

[5] De Lange, A.H. (2005). What about causality? Examining longitudinal relations between work characteristics and mental health. Ridderprint, BV: Ridderkerk,.

[6] Dofradottir, A \& Hogh, A. (2002). Bullying at work: A critical review of Danish and international research. AMI Dok, 10, 3-71.

[7] Dormann, C. \& Zapf, D. (1999). Social support, social stressors at work and depressive symptoms: Testing for main and moderating effects with structural equations in a three-wave longitudinal study. Journal of Applied Psychology, 84, 878-884.

[8] Dormann, C. \& Zapf, D. (2002). Social stressors at work, irritation, and depressive symptoms: Accounting for unmeasured third variables in a multi-wave study. Journal of Occupational and Organizational Psychology, 75, 33-58.

[9] Einarsen, S. (2000). Harassment and bullying at work: a review of the Scandinavian approach. Aggressive Violent Behaviour, 5(4), 379-401.

[10] Einarsen, S. \& Mikkelsen, E.G. (2000). Bullying at work: what is and what do we know about it? Tidsskr Arbliv, 2(1), 7-24.

[11] Einarsen, S. \& Mikkelsen, E.G. (2003). Individual effects of exposure to bullying at work. In S. Einarsen, H. Hoel, D. Zapf, \& CL Cooper (Eds.). Bullying and emotional abuse in the workplace. International perspectives in research and practice (pp. 127-144). London: Taylor \& Francis.

[12] Einarsen, S., Hoel, H., Zapf, D. \& Cooper, CL. (2003). The concept of bullying at work. The European tradition. In S. Einarsen, H. Hoel, D. Zapf \& CL Cooper (Eds.). Bullying and emotional abuse in the workplace. International perspectives in research and practice (pp.3-30). London: Taylor \& Francis.

[13] Einarsen, S., Hoel, H., \& Notelaers, G. (2009). Measuring exposure to bullying and harassment at work: Validity, factor structure and psychometric properties of the Negative Acts QuestionnaireRevised. Work \& Stress, 23(1), 24-44. 
[14] Evers, A., Frese, M., \& Cooper, C. L. (2000). Revisions and further developments of the Occupational Stress Indicator: LISREL results from four Dutch studies. Journal of Occupational \& Organizational Psychology, 73(2): 221-240.

[15] Finne, LB, Knardahl, S \&Lau, B. (2011). Workplace bullying and mental distress- a prospective study of Norwegian employees. Scandinavian Journal of Environmental Health, 37(4), 276-287.

[16] Hansen, A.M., Hogh, A., Persson, R., Karlson, B., Garde, A.H., \& Orbaek, P. (2006). Bullying at work, health outcomes, and physiological stress response. Journal of Psychosomatic Stress, 60, 63-72.

[17] Hogh, A., Henriksson, ME, \& Burr, A. (2005). A 5-year follow-up study of aggression at work and psychological health. International Journal of Behavioural Medicine, 12(4), 256-265.

[18] Kivimaki, M, Virtanen, M, Vartia, M, Elovainio, M, Vahtera, J\& Keltikangas-Jarvinen, J. (2002). Workplace bullying and the risk of cardiovascular disease and depression. Occupational Environmental Medecine, 60, 779-783.

[19] Neuman, J.H. \& Baron, R.A. (1997). Aggression in the workplace. In: Giacalone RA, Greenberg, J., editors. Antisocial behaviour in organizations. London: Sage Publications, 37-67.

[20] Niedhammer, I., David, S. \& Degioanni, S. (2006). Association between workplace bullying and depressive symptoms in the French working population. Journal of Psychosomatic Results, 61(2), 251259. doi:10.1016/j.jpsychores.2006.03.051.

[21] Nielsen, M.B., Hetland, J., Matthiesen, S.B. \& Einarsen, S. (2012). Longitudinal relationships between workplace bullying and psychological distress. Scandinavian Journal of Work, Environment and Health, 38(1), 38-46.

[22] Notelaers, G., Einarsen, S., De Witte, H. \& Vermunt, J. (2006). Measuring exposure to bullying at work: The validity and advantages of latent class cluster approach. Work \& Stress, 20, 288-301.

[23] Rayner, C., Hoel, H. \& Cooper, C.L. (2002). Workplace bullying. What We Know, Who is to Blame, and What We Can Do? London: Taylor and Francis.

[24] Rodriguez-Munoz, A., Baillien, E., De Witte, H., Moreno-Jimenez, B. \& Pastor, J.C. (2009). Crosslagged relationships between workplace bullying, job satisfaction and egagement: Two longitudinal studies. Journal of Work \& Stress, 23(3), 225-243.

[25] Rodriguez-Munoz, A., Moreno-Jimenez, B. \& Sanz-Vergel, A.I. (2015). Reciprocical relations between workplace bullying, anxiety and vigor: a two-wave longitudinal study. Anxiety, Stress \& Coping: An International Journal. DOI:10.1080/10615806.2015.1016003.

[26] Rospenda,K.M., Richman, J.A. \& Shannon, C.A. (2006). Patterns of workplace harassment, gender, and use of services: An update. Journal of Occupational Health Psychology, 11, 379-393.

[27] Rugulies, R., Madsen, IEH, Hjarbech, PU, Hogh, A., Borg, V., Carneiro, IG \& Aust, B. (2012). Bullying at work and onset of a major depressive episode among Danish female eldercare workers. Scandinavian Journal of Work, Environment \& Health, 38(3), 218-227.

[28] Salin, D. (2003). Ways of explaining workplace bullying: a review of enabling, motivating and precipitating structures and processes in the work environment. Human Relations, 56(10), 1213-1232.

[29] Steinmetz, H., Frese, M. \& Schmidt, P. (2008). A longitudinal panel study on antecedents and outcomes at work-home interference. Journal of Vocational Behavior, 73, 231-241.

[30] Taris, T. \& Kompier, M. (2003). Challenges of longitudinal designs in occupational health-psychology. Scandinavian Journal Work, Environment and Health, 29, 1-4.

[31] Vartia, M. (2001). Consequences of workplace bullying with respect to the well-being of its targets and the observers of bullying. Scandinavian Journal of Work Environmental Health, 27(1), 63-69.

[32] Zapf, D., Knorz, C. \& Kulla, M. (1996). On the relationship between mobbing factors, and job content, the social work environment and health outcomes. European Journal of Work and Organisational Psychology, 5(2), 215-237.

[33] Zapf, D. \& Einarsen, S. (2001). Bullying in the workplace: recent trends in research and practice- an introduction. European Journal of Work and Organisational Psychology, 10(4), 369-373. 